\title{
Diabetic corneal neuropathy: clinical perspectives
}

This article was published in the following Dove Press journal:

Clinical Ophthalmology

\author{
Guzel Bikbova ${ }^{1,2}$ \\ Toshiyuki Oshitari' \\ Takayuki Baba' \\ Mukharram Bikbov ${ }^{2}$ \\ Shuichi Yamamoto' \\ 'Department of Ophthalmology and \\ Visual Science, Chiba University \\ Graduate School of Medicine, Chiba, \\ Japan; ${ }^{2}$ Cornea and Refractive Surgery \\ Department, Ufa Eye Research \\ Institute, Ufa, Russia
}

\begin{abstract}
Diabetic keratopathy is characterized by impaired innervation of the cornea that leads to decreased sensitivity, with resultant difficulties with epithelial wound healing. These difficulties in wound healing put patients at risk for ocular complications such as surface irregularities, corneal infections, and stromal opacification. Pathological changes in corneal innervations in diabetic patients are an important early indicator of diabetic neuropathy. The decrease in corneal sensitivity is strongly correlated with the duration of diabetes as well as the severity of the neuropathy. This review presents recent findings in assessing the ocular surface as well as the recent therapeutic strategies for optimal management of individuals with diabetes who are susceptible to developing diabetic neuropathy.
\end{abstract}

Keywords: diabetes mellitus, cornea, innervation, neuroprotective therapy

\section{Introduction}

The incidence of diabetes has risen markedly in the past four decades from 108 million in 1980 to 422 million in 2014. ${ }^{1}$ According to the US National Diabetes Statistics Reports (2017), 30.3 million people (9.4\% of the US population) of all ages had diabetes in $2015 .^{2}$

Diabetic neuropathies are characterized by the progressive loss of nerve fibers a common complication affecting $\sim 50 \%$ of patients with diabetes mellitus. ${ }^{3}$ These complications can occur in the cornea and can lead to diabetic neuropathy, severe reductions in visual acuity, and eventual blindness.

Diabetic retinopathy is generally considered to be a microvascular complication based on the ophthalmoscopic observations of the ocular fundus; however, growing evidence indicates that the appearance of the neuroretinal damage develops simultaneously as, or even prior to, the vascular changes. ${ }^{4-7}$ Evaluation of the neuronal changes at the early stages of diabetes mellitus is therefore very important.

Although increasing attention has been paid to disorders of the ocular surface in the eyes of patients with diabetes, there is a lack of review articles on the management of diabetic keratopathy. Thus, the purpose of this review is to present the findings in recent publications that discuss the clinical perspectives for ocular surface management in patients with diabetes mellitus.

\section{Corneal surface}

The corneal epithelium plays an important role as an ocular surface defense system by providing both a physical and an immunological barrier to external organic and inorganic agents. ${ }^{8}$ Innervation of the cornea is derived from the ophthalmic division of the trigeminal nerve; this provides the cornea with a large number of sensory receptors, such as the myelinated A- $\delta$ and unmyelinated $C$ fibers, with $\sim 7,000$ epithelial free nerve endings per square millimeter, which is 300-600 times greater than that of the skin. ${ }^{9}$
Department of Ophthalmology and Visual Science, Chiba University Graduate School of Medicine, Inohana I-8-I, Chuo-ku, Chiba 260-8670, Chiba, Japan Tel +8I 432262124

Fax +81432244162

Email gbikbova@gmail.com 
The maintenance of the corneal sensitivity, blink reflex, homeostasis of the ocular surface, and the regulation of corneal wound healing is led by corneal innervation. ${ }^{9}$ As a result, impairment of corneal innervation can lead to an attenuation of corneal sensitivity as well as dry eye, neurotrophic keratitis, and even blindness. ${ }^{10}$ Hyperglycemia in patients with diabetes can cause impaired corneal sensitivity, reduced nerve fiber density, and delayed epithelial wound healing. ${ }^{11}$ Recent studies have demonstrated the important role of glycation in the pathogenesis of retinal diabetic neuropathy and as part of different trigger mechanisms resulting in neuronal dysfunction. ${ }^{6,7}$ Kim et al showed that advanced glycation end products (AGEs), 8-OHdG, and NF- $\mathrm{KB}$ were expressed at higher levels in the cornea of diabetic rats than in that of healthy control rats, suggesting that these factors probably participated in apoptosis and the subsequent changes of the cornea that are related to diabetic keratopathy. ${ }^{12}$

Because of the reduced corneal sensitivity in patients with diabetes mellitus, there is a decrease in both reflex-induced lacrimal secretion and blink rate, and these reductions result in greater tear evaporation. These changes will then put patients with diabetes at a risk of developing dry eyes. ${ }^{13}$

Tear-film dysfunction and chronic tear-secretion deficiency can also be present in patients with diabetes, as their tear lipid thickness, tear quantity, and tear stability are significantly decreased. ${ }^{14}$ The recent study by Kesarwani et al on tear film dysfunction in diabetes in the Indian population demonstrated decreased tear secretion and stability, evidence of keratoepitheliopathy, abnormal results on the rose bengal staining test, squamous metaplasia, and poor goblet cell density. ${ }^{15}$

Furthermore, diabetes mellitus can cause changes in the epithelial basal cells, basement membrane, and the sub-basal nerve plexus (SBN) leading to epitheliopathy and corneal adhesion disorders. ${ }^{16}$ Moreover, a loss of corneal nerves leads to a reduced supply of trophic neuropeptides, resulting in prolonged healing time. ${ }^{8}$

Another finding in diabetic corneas is increased corneal thickness; however, there is no significant correlation between the severity of retinopathy and the corneal thickness. ${ }^{17-19}$

Ultrastructural changes in the corneal stroma can be explained by the increased accumulation of AGEs which then leads to non-enzymatic cross-linking between collagen molecules and proteoglycans, thereby causing stiffening and thickening of the cornea. ${ }^{20}$

A less common change in diabetic corneas is the presence of vertical lines at the level of Descemet's membrane and endothelium. These lines were initially described first by Waite and Beetham and then by Henkind and Wise..$^{21,75,76}$
Morphological changes have been reported in the diabetic corneal endothelium. Experimental studies have shown that there is a decrease in the corneal endothelial cell density and hexagonality, and an increase polymegathism. These changes indicate there is an increase in morphological abnormalities or pleomorphism in the corneal endothelium in individuals with diabetes. ${ }^{22-27}$

\section{Corneal surface assessments}

In vivo confocal microscopy (IVCM) has become the standard method of assessing the cornea at a cellular level, both in diseased and healthy eyes. Many studies have reported on the advantages of using IVCM for analysis of the sub-basal nerve plexus (eg, the central cornea and the inferior whorl) for the clinical diagnosis of early peripheral neuropathy. ${ }^{28-32}$ Petropoulos et al reported that the nerve fiber density of the inferior region of the cornea was more sensitive to early nerve fiber damage than the central corneal region in patients with diabetes before the development of peripheral neuropathy. ${ }^{33}$

Recent IVCM studies by Qu et al showed an increase in the densities of Langerhan cells and a decrease of density in the sub-basal nerve plexus in patients with type 2 diabetes mellitus who have corneal punctate epitheliopathy. These changes were related to a lower basal epithelial cell density leading to a delay in corneal epithelium healing. ${ }^{34}$ Lagali et al went further by assessing raw images obtained by laserscanning IVCM of 82 eyes that had been automatically processed to produce depth-corrected, wide-area mosaic images of the continuous nerve fiber paths and nerve and background intensity levels. These wide-area mosaic images produced from 82 eyes by laser-scanning IVCM showed a progressive degeneration of the sub-basal nerve plexus with increasing duration of type 2 diabetes..$^{35}$ They reported that comparisons of mosaics from newly diagnosed subjects (diabetes diagnosed $<1$ year prior to the IVCM examination) to subjects with long-term diagnosed diabetes (diagnosed $>20$ years prior to the IVCM examination) showed a marked degeneration of the sub-basal plexus. A predominant loss of the nerves occurred outside the whole region along with the loss of short, thin nerve branch segments.

The appearance of neuronal damage in early stages of diabetes has been demonstrated in laboratory studies, ${ }^{4-7}$ and the findings have been described clinically in a study by Srinivasan et al, who examined the neuronal structural integrity of the cornea and retina as markers for neuronal degeneration in non-proliferative diabetic retinopathy. ${ }^{36}$ They assessed the corneal nerve fiber length (CNFL), corneal nerve branch density (CNBD), and the corneal nerve fiber tortuosity (CNFT), and reported that shorter CNFLs were significantly 
associated with the severity of the nonproliferative diabetic retinopathy, CNBD, and CNFT. According to Srinivasan et al, CNFL may be a better marker, than CNBD and CNFT, for detecting corneal neuronal degeneration in patients with mild nonproliferative diabetic retinopathy, compared with controls and those with diabetes but without retinopathy. ${ }^{36}$

Bitirgen et al confirmed that corneal nerve abnormalities developed before the first signs of diabetic retinopathy. They found that patients with diabetes mellitus without retinopathy and non-proliferative diabetic retinopathy had decreased basal epithelial cell density, anterior stromal keratocyte counts, and endothelial cell density. Moreover, they confirmed an inverse correlation of these parameters with the duration of diabetes mellitus. ${ }^{37}$ However, the reductions of nerve fiber density, nerve branch density, and nerve fiber length were found only in patients without the usual signs of diabetic retinopathy, were progressive, and worsened with increasing severity of retinopathy. ${ }^{37}$ Bitirgen et al reported a lower keratocyte density in the anterior part of the cornea in patients with proliferative diabetic retinopathy than in patients without diabetic retinopathy. In addition, they reported that the reduction in the anterior stromal keratocyte density was significantly correlated with the duration of diabetes mellitus. ${ }^{37}$

Accumulation of AGE products in patients with diabetes mellitus can cause protein glycation, which can explain the pathological changes of the cornea in the initial stages of diabetes. ${ }^{38}$

An interesting recent study has suggested that the expression of insulin-like growth factor binding protein-3 (IGFBP-3) in basal tears of patients with type 2 diabetes mellitus can be an indicator of ocular damage. ${ }^{39}$ This association was present because the concentration of IGFBP-3 in the tear fluid was increased approximately threefold in eyes with diabetic retinopathy. ${ }^{39}$ The increase was not directly related to the blood sugar level because there was only a weak or modest correlation between the HbAlc level and both the nerve fiber branch density and nerve fiber length. In addition, the level of $\mathrm{HbA} 1 \mathrm{c}$ was not significantly correlated with the concentration of IGFBP-3 in tears. These findings suggested that whereas IGFBP-3 may be a good indicator for the presence of corneal damage in patients with diabetes, it is not directly related to blood sugar control. ${ }^{39}$

Di et al detected an excessive inflammatory response in diabetic corneas, which was manifested by the accumulation of polymorphonuclear cells in mice diabetic corneas. Wound healing in diabetic corneas was delayed and was accompanied by elevated levels of proinflammatory cytokines, which resulted from the excessive inflammatory response. ${ }^{40}$
Ehmke et al used nonlinear two-photon microscopy (TPM) for in vivo imaging of the cornea of streptozotocindiabetic Thy1-YFP mice. ${ }^{41}$ The difference between confocal and nonlinear microscopy is with their signal detection methods. In confocal microscopy, signals are generated by a linear process and are detected in the focal plane. In TPM, nonlinear signals are generated within the focal volume of the laser spot as a result of nonlinear processing. ${ }^{41}$ The authors noted that TPM was helpful in identifying early signs of diseases in animal models in vivo and can be recommended for further clinical studies.

\section{New approaches in treatment of the ocular surface in patients with diabetes}

The first treatment of corneal neuropathy should be systemic therapy for diabetes in order to attain accurate control of blood glucose level. Successful control should slow further progression of diabetic neuropathies. The successful management of neurotrophic keratopathy is generally based on achieving epithelial healing and preventing the progression of corneal damage. However, pathogenetically orientated pharmacological treatments are, so far, unavailable for neurotrophic keratopathy.

New systemic drugs have been introduced to treat diabetes, including: glutazumab, a novel long-lasting GLP-1/antiGLP-1R antibody fusion protein; ${ }^{42}$ beta-carotene, reported to improve diabetes-related ultrastructural changes of the cornea in diabetic rats; ${ }^{43}$ oral administration of resolvin-D1, an antiinflammatory eicosanoid, together with fish oil, reported to reduce corneal nerve degeneration in diabetic rats; ${ }^{44}$ and a combination of menhaden oil, $\alpha$-lipoic acid, and enalapril, shown to reverse diabetic corneal and peripheral neuropathy in streptozotocin-induced diabetic rats. ${ }^{45}$

Cell-based therapies have been reported as an option for preventing neurovascular damage and promoting regeneration of the damaged retina. ${ }^{46-50}$ The ability of mesenchymal stem cells to produce neuroprotective and neurotrophic factors, and the potential of endothelial progenitor cells to repair vasculature have been suggested to be helpful in treating early and moderately damaged retina. ${ }^{46} \mathrm{Di}$ et al demonstrated that a local transplantation of bone marrow-derived mesenchymal stem cells could suppress excessive inflammatory responses, activate endogenous corneal progenitor cells, promote alternative polarization of infiltrated macrophages, and enhance repair of diabetic corneal wounds. ${ }^{40}$

Gene therapy is another approach for managing diabetic keratopathy. The goal of this method is to set one diseaseassociated target with high specificity and affect it through either a gain or loss of the function of the targeted gene. ${ }^{40}$ 
It was reported that adenoviral gene therapy with overexpression of the c-met proto-oncogene and/or silencing of matrix metalloproteinase-10 and cathepsin F normalized epithelial wound healing and stem cell marker expression in human organ-cultured diabetic corneas. ${ }^{51,52}$

There has been a recent increase in interest in the dynamic role of microRNAs (miRNAs) in the modulation of tissue homeostasis. The study by Kulkarni et al, identified miRNA expression profiles in normal and diabetic human limbal cells, and a differential expression of a number of miRNAs have been found in normal corneas and those of both type 1 and type 2 diabetes mellitus. Because of the differential expression of a subset of miRNAs between type 1 and 2 diabetes mellitus, it was suggested that type 1 and type 2 diabetes are different diseases although they have the same clinical manifestations and complications. ${ }^{53}$ The miR-10b miRNAs were found to control corneal epithelial homeostasis and stem cell functions. This suggested that miR-10b might be a candidate for functional studies of limbal progenitor cells in normal and disease states and potentially as new therapy for diabetic keratopathy. ${ }^{53}$

There are relatively few therapeutic treatments available for regulating the functions of the corneal nerve and recovery of corneal innervations in patients with diabetic neuropathy. Some studies have reported, however, that the use of neurotrophic factors might be potential therapy for corneal nerve recovery. Neurotrophic factors are molecules that regulate the growth and survival of developing neurons, and they also participate in the maintenance of mature neurons in both the central and peripheral nervous systems. Factors such as nerve growth factor (NGF), glial cell-derived neurotrophic factor (GDNF), and ciliary neurotrophic factor (CNTF) have been reported to stimulate corneal epithelial cell proliferation and migration as well as to enhance their immunoprotective function through their receptors in the corneal epithelium. ${ }^{54-57}$

A recent study demonstrated that the neurotrophic factors, NGF and GDNF - derived from corneal epithelial cells are involved in corneal nerve regeneration, which can be impaired by hyperglycemia. ${ }^{58}$ Topical application of NGF reversed the apoptosis and inflammation in the cornea by promoting the formation of reactive oxygen species (ROS) in both in vitro and in vivo diabetic models. ${ }^{59}$

Our previous review ${ }^{60}$ presented the importance of neurotrophic factors and their potential use for restoration of corneal nerves in diabetic patients, together with a discussion of the potential of neurotrophic factors application for neuroprotective and neuroregenerative therapy, with a possibility to reverse the damage to peripheral corneal nerves.
Semaphorins belong to a class of membrane-bound proteins, and they are reported to act as axon-guidance proteins. ${ }^{61}$ In vivo studies have demonstrated that they can induce nerve regeneration when administrated into the corneal intrastromal micropocket without inhibition of NGF. ${ }^{61}$

The aim of local treatments for diabetic keratopathy is to maintain a smooth and lubricated ocular surface with an intact epithelium and adequate blink response. This minimizes visual distortions and maximizes comfort. Agents such as topical antibiotics, bandage contact lenses, preservative-free artificial tears, amniotic membrane transplantation, tarsorrhaphy, and the conjunctival flap technique are methods that have been used to treat refractory neurotrophic corneal ulcers. $^{62}$ An aldose reductase inhibitor, epalrestat, which is known to prevent protein glycation, was proposed by Alvarez-Rivera et al. It was suggested that it be used in silicon hydrogel contact lenses to provide a constant slow release of epalrestat in treating diabetic-related corneal damage. ${ }^{63}$

Corneal epithelial defects can develop from surgical procedures on diabetic patients, and these are usually managed by an application of topical lubricants and prophylactic antibiotics. Chen et al reported that the incidence of persistent corneal epithelial defects after vitrectomy was $4.8 \% .{ }^{64}$ This is why the healing of corneal epithelial defects must be accomplished as soon as possible for the vital care of the corneas of diabetic patients.

The use of 0.5 units of topical insulin QID was demonstrated to be effective in healing corneal epithelial defects after vitrectomy in diabetic patients in a randomized control trial presented by Fai et al. ${ }^{65}$ Thymosin beta 4 (T $\left.\beta 4\right)$, a naturally occurring polypeptide, has been used in diabetic patients, and its use has led to a significant reduction of nonhealing epithelial defects in diabetic patients. $\mathrm{T} \beta_{4}$ has been proposed to be a promising therapy for diabetic keratopathy. ${ }^{66}$ Substance P (SP) is a neuropeptide that is released from sensory nerve fibers, and it has been demonstrated that it has an ability to promote corneal epithelial wound healing in diabetic subjects. The results of a recent study showed an improvement of mitochondrial function, recovery of corneal sensation, and decreasing levels of ROS caused by hyperglycemia. ${ }^{67}$

Sodium hyaluronate (HA) has the potential to bind water due to the sponge-like structure of the polysaccharide chains, and it can slowly release the water molecules, thereby acting as a reservoir. It was reported to be effective in promoting corneal epithelial regeneration, improving corneal sensitivity, and increasing the density of corneal nerve fibers and conjunctival goblet cells in diabetic mice. ${ }^{68}$ The effective concentration of HA was $0.3 \% .{ }^{68}$ Topical application of the 
synergy peptide PHSRN - a fibronectin-derived peptide significantly facilitated the healing of corneal epithelial wounds in diabetic rats. ${ }^{69}$ Topical application of pigment epithelium-derived factor (PEDF) in combination with docosahexaenoic acid (DHA) has been reported to lead to significant increases in corneal epithelial nerve regeneration and substance $\mathrm{P}$-positive nerve density in both injured and intact corneas of diabetic mice. Additionally, an elevation of the corneal sensitivity and tear production was noted in the treated corneas. ${ }^{70}$ The intranasal delivery of a nanomicelle curcumin solution promoted corneal epithelial/nerve healing in diabetic mice by delivering the pharmaceutically active ingredients to the trigeminal neurons, thus helping to heal diabetic corneal epithelial cells and nerve wounds. ${ }^{71}$ An extract of aloe vera has been reported to promote corneal wound healing in diabetic rats, ${ }^{72}$ and topical lacritin delivered by elastin-like polypeptide based nanoparticle improved the regeneration of corneal epithelium in non-obese diabetic mice. ${ }^{73}$ However, most of the suggested therapies have been determined by experiments on animal models, and further clinical studies are needed to provide an effective care routine for patients with diabetes. A summary of the advances in the treatment of diabetic keratopathy is presented in Table 1.

Table I Advances in the treatment of diabetic corneal disease

\begin{tabular}{|c|c|c|}
\hline Therapy & Administration & References \\
\hline $\begin{array}{l}\text { Glutazumab (long-acting } \\
\text { GLP-I/anti-GLP-IR } \\
\text { antibody fusion protein) }\end{array}$ & Systematic & Li et $\mathrm{al}^{42}$ \\
\hline Beta-carotene & Systematic & $\begin{array}{l}\text { Abdul-Hamid } \\
\text { and Moustafa }{ }^{43}\end{array}$ \\
\hline Resolvin-DI & Systematic & Shevalye et $\mathrm{al}^{44}$ \\
\hline $\begin{array}{l}\text { Combination therapy of } \\
\text { menhaden oil, } \alpha \text {-lipoic } \\
\text { acid, and enalapril }\end{array}$ & Systematic & Davidson et $\mathrm{al}^{45}$ \\
\hline $\begin{array}{l}\text { Gene therapy of limbal } \\
\text { cells }\end{array}$ & & Saghizadeh et $\mathrm{al}^{51}$ \\
\hline Stem cell therapy & & Di et $\mathrm{al}^{40}$ \\
\hline Substance P & Eye drops & Yang et $\mathrm{al}^{67}$ \\
\hline Insulin & Eye drops & Fai et $a^{65}$ \\
\hline $\begin{array}{l}\text { Thymosin beta- } 4 \\
\text { PEDF in combination } \\
\text { with DHA }\end{array}$ & Eye drops & $\begin{array}{l}\text { Sosne et } \mathrm{al}^{66} \\
\text { He et } \mathrm{al}^{70}\end{array}$ \\
\hline CNTF & Subconjunctival injection & Zhou et $\mathrm{al}^{74}$ \\
\hline NGF & Eye drops & Park et $\mathrm{al}^{59}$ \\
\hline Nanomicelle curcumin & Intranasal administration & Guo et $\mathrm{al}^{71}$ \\
\hline Semaphorins & $\begin{array}{l}\text { Injection to intrastromal } \\
\text { micropocket }\end{array}$ & Zhang et $\mathrm{al}^{61}$ \\
\hline Extract of aloe vera & Eye drops & Atiba et $\mathrm{al}^{72}$ \\
\hline Epalrestat, in silicon & Silicon hydrogel contact & Alvarez-Rivera \\
\hline $\begin{array}{l}\text { hydrogel contact lenses } \\
\text { HA }\end{array}$ & $\begin{array}{l}\text { lenses } \\
\text { Eye drops }\end{array}$ & $\begin{array}{l}\text { et } \mathrm{al}^{63} \\
\text { Di et } \mathrm{al}^{68}\end{array}$ \\
\hline $\begin{array}{l}\text { Fibronectin-derived } \\
\text { peptide PHSRN }\end{array}$ & Eye drops & Morishige et $\mathrm{al}^{69}$ \\
\hline
\end{tabular}

Abbreviations: GLP-I, glucagon-like peptide-I; PEDF, pigment epithelium-derived factor; DHA, docosahexaenoic acid; CNTF, ciliary neurotrophic factor; NGF, nerve growth factor; HA, sodium hyaluronate.

\section{Conclusion}

Evaluations of the diabetic ocular surface are very important for all physicians, and not just for ophthalmologists. Assessments of the corneal nerve parameters can detect early indicators for the development of diabetic neuropathy and can also be used to monitor the course of diabetes. Using different imaging techniques such as IVCM and nonlinear two-photon microscopy should be very helpful methods for in vivo examination of the corneal structure at the cellular level. Although there is still no unified routine care available for the management of the cornea in diabetic individuals, recently published therapeutic agents including targeted molecular therapies (eg, gene and stem cell therapies) appear promising. Further investigations to establish pathogenetically orientated therapy for diabetic neuropathy bringing animal models to clinical trials should be one of the main focuses of future research.

\section{Acknowledgments}

This paper is supported by a Grant-in Aid from the Ministry of Education, Science, Sports and Culture of the Japanese Government. The authors would like to thank Professor Duco Hamasaki of the Bascom Palmer Eye Institute of the University of Miami for discussions and editing the manuscript.

\section{Author contributions}

All authors contributed toward data analysis, drafting and revising the paper and agree to be accountable for all aspects of the work.

\section{Disclosure}

The authors report no conflicts of interest in this work.

\section{References}

1. Mathers CD, Loncar D. Projections of global mortality and burden of disease from 2002 to 2030. PLoS Med. 2006;3(11):e442.

2. Centers for Disease Control and Prevention National Diabetes Statistics Reports (2017). Available from: https://www.cdc.gov/diabetes/pdfs/data/ statistics/national-diabetes-statistics-report.pdf. Accessed November 21, 2017.

3. Boulton AJ, Vinik AI, Arezzo JC, et al; American Diabetes Association. Diabetic neuropathies: a statement by the American Diabetes Association. Diabetes Care. 2005;28(4):956-962.

4. Oshitari T, Dezawa M, Okada S, et al. The role of c-fos in cell death and regeneration of retinal ganglion cells. Invest Ophthalmol Vis Sci. 2002; 43(7):2442-2449.

5. Oshitari T, Bikbova G, Yamamoto S. Increased expression of phosphorylated c-Jun and phosphorylated c-Jun N-terminal kinase associated with neuronal cell death in diabetic and high glucose exposed rat retinas. Brain Res Bull. 2014;101:18-25.

6. Bikbova G, Oshitari T, Baba T, Yamamoto S. Altered expression of NF- $\kappa$ B and SP1 after exposure to advanced glycation end-products and effects of neurotrophic factors in AGEs exposed rat retinas. $J$ Diabetes Res. 2015;2015:543818. 
7. Bikbova G, Oshitari T, Baba T, Yamamoto S. Mechanisms of neuronal cell death in AGE-exposed retinas - research and literature review. Curr Diabetes Rev. 2017;13(3):280-288.

8. Leong YY, Tong L. Barrier function in the ocular surface: from conventional paradigms to new opportunities. Ocul Surf. 2015;13(2): 103-109.

9. Müller LJ, Marfurt CF, Kruse F, Tervo TM. Corneal nerves: structure, contents and function. Exp Eye Res. 2003;76(5):521-542.

10. Shaheen BS, Bakir M, Jain S. Corneal nerves in health and disease. Surv Ophthalmol. 2014;59(3):263-285.

11. He J, Bazan HE. Mapping the nerve architecture of diabetic human corneas. Ophthalmology. 2012;119(5):956-964.

12. Kim J, Kim CS, Sohn E, Jeong IH, Kim H, Kim JS. Involvement of advanced glycation end products, oxidative stress and nuclear factorkappaB in the development of diabetic keratopathy. Graefes Arch Clin Exp Ophthalmol. 2011;249(4):529-536.

13. The definition and classification of dry eye disease: report of the Definition and Classification Subcommittee of the International Dry Eye WorkShop (2007). Ocul Surf. 2007;5(2):75-92.

14. Zhang X, Zhao L, Deng S, Sun X, Wang N. Dry eye syndrome in patients with diabetes mellitus: prevalence, etiology, and clinical characteristics. J Ophthalmol. 2016;2016:8201053.

15. Kesarwani D, Rizvi SWA, Khan AA, Amitava AK, Vasenwala SM, Siddiqui Z. Tear film and ocular surface dysfunction in diabetes mellitus in an Indian population. Indian J Ophthalmol. 2017;65(4):301-304.

16. Holland EJ, Mannis MJ, Lee WB. Ocular Surface Disease: Cornea, Conjunctiva and Tear Film. London: Elsevier/Saunders; 2013.

17. Toygar O, Sizmaz S, Pelit A, Toygar B, Yabaş Kiziloğlu Ö, Akova Y. Central corneal thickness in type II diabetes mellitus: is it related to the severity of diabetic retinopathy? Turkish J Med Sci. 2015;45(3): 651-654.

18. Ozdamar Y, Cankaya B, Ozalp S, Acaroglu G, Karakaya J, Ozkan SS. Is there a correlation between diabetes mellitus and central corneal thickness? J Glaucoma. 2010;19(9):613-616.

19. Nishitsuka K, Kawasaki R, Kanno M, et al; Funagata Study. Determinants and risk factors for central corneal thickness in Japanese persons: the Funagata Study. Ophthalmic Epidemiol. 2011;18(5):244-249.

20. Zou C, Wang S, Huang F, Zhang YA. Advanced glycation end products and ultrastructural changes in corneas of long-term streptozotocininduced diabetic monkeys. Cornea. 2012;31(12):1455-1459.

21. Mocan MC, Irkeç M, Orhan M. Evidence of Waite-Beetham lines in the corneas of diabetic patients as detected by in vivo confocal microscopy. Eye (Lond). 2006;20(12):1488-1490.

22. Leem HS, Lee KJ, Shin KC. Central corneal thickness and corneal endothelial cell changes caused by contact lens use in diabetic patients. Yonsei Med J. 2011;52(2):322-325.

23. Urban B, Raczyńska D, Bakunowicz-Łazarczyk A, Raczyńska K, Krętowska M. Evaluation of corneal endothelium in children and adolescents with type 1 diabetes mellitus. Mediators Inflamm. 2013;2013: 913754.

24. Storr-Paulsen A, Singh A, Jeppesen H, Norregaard JC, Thulesen J. Corneal endothelial morphology and central thickness in patients with type II diabetes mellitus. Acta Ophthalmol. 2014;92(2):158-160.

25. Misra SL, Goh YW, Patel DV, Riley AF, McGhee CN. Corneal microstructural changes in nerve fiber, endothelial and epithelial density after cataract surgery in patients with diabetes mellitus. Cornea. 2015; 34(2):177-181.

26. Dhasmana R, Singh IP, Nagpal RC. Corneal changes in diabetic patients after manual small incision cataract surgery. J Clin Diagn Res. 2014; 8(4):VC03-VC06.

27. Lass JH, Riddlesworth TD, Gal RL, et al; Cornea Donor Study Research Group. The effect of donor diabetes history on graft failure and endothelial cell density 10 years after penetrating keratoplasty. Ophthalmology. 2015;122(3):448-456.

28. Pritchard N, Edwards K, Russell AW, Perkins BA, Malik RA, Efron N. Corneal confocal microscopy predicts 4-year incident peripheral neuropathy in type 1 diabetes. Diabetes Care. 2015;38(4):671-675.
29. Misra SL, Craig JP, Patel DV, et al. In vivo confocal microscopy of corneal nerves: an ocular biomarker for peripheral and cardiac autonomic neuropathy in type 1 diabetes mellitus. Invest Ophthalmol Vis Sci. 2015;56(9):5060-5065.

30. Petropoulos IN, Alam U, Fadavi H, et al. Corneal nerve loss detected with corneal confocal microscopy is symmetrical and related to the severity of diabetic polyneuropathy. Diabetes Care. 2013;36(11):3646-3651.

31. Pritchard N, Edwards K, Dehghani C, et al. Longitudinal assessment of neuropathy in type 1 diabetes using novel ophthalmic markers (LANDMark): study design and baseline characteristics. Diabetes Res Clin Pract. 2014;104(2):248-256.

32. Pritchard N, Dehghani C, Edwards K, et al. Utility of assessing nerve morphology in central cornea versus whorl area for diagnosing diabetic peripheral neuropathy. Cornea. 2015;34(7):756-761.

33. Petropoulos IN, Ferdousi M, Marshall A, et al. The inferior whorl for detecting diabetic peripheral neuropathy using corneal confocal microscopy. Invest Ophthalmol Vis Sci. 2015;56(4):2498-2504.

34. Qu JH, Li L, Tian L, Zhang XY, Thomas R, Sun XG. Epithelial changes with corneal punctate epitheliopathy in type 2 diabetes mellitus and their correlation with time to healing. BMC Ophthalmol. 2018;18(1):1.

35. Lagali NS, Allgeier S, Guimarães $\mathrm{P}$, et al. Reduced corneal nerve fiber density in type 2 diabetes by wide-area mosaic analysis. Invest Ophthalmol Vis Sci. 2017;58(14):6318-6327.

36. Srinivasan S, Dehghani C, Pritchard N, et al. Corneal and retinal neuronal degeneration in early stages of diabetic retinopathy. Invest Ophthalmol Vis Sci. 2017;58(14):6365-6373.

37. Bitirgen G, Ozkagnici A, Malik RA, Kerimoglu H. Corneal nerve fibre damage precedes diabetic retinopathy in patients with type 2 diabetes mellitus. Diabet Med. 2014;31(4):431-438.

38. Sato E, Mori F, Igarashi S, et al. Corneal advanced glycation end products increase in patients with proliferative diabetic retinopathy. Diabetes Care. 2001;24(3):479-482.

39. Stuard WL, Titone R, Robertson DM. Tear levels of insulin-like growth factor binding protein 3 correlate with subbasal nerve plexus changes in patients with type 2 diabetes mellitus. Invest Ophthalmol Vis Sci. 2017;58(14):6105-6112.

40. Di G, Du X, Qi X, et al. Mesenchymal stem cells promote diabetic corneal epithelial wound healing through TSG-6-dependent stem cell activation and macrophage switch. Invest Ophthalmol Vis Sci. 2017; 58(10):4344-4354.

41. Ehmke T, Leckelt J, Reichard M, et al. In vivo nonlinear imaging of corneal structures with special focus on BALB/c and streptozotocindiabetic Thy1-YFP mice. Exp Eye Res. 2016;146:137-144.

42. Li C, Yang M, Wang X, et al. Glutazumab, a novel long-lasting GLP-1/ anti-GLP-1R antibody fusion protein, exerts anti-diabetic effects through targeting dual receptor binding sites. Biochem Pharmacol. 2018;150: $46-53$.

43. Abdul-Hamid M, Moustafa N. Amelioration of alloxan-induced diabetic keratopathy by beta-carotene. Exp Toxicol Pathol. 2014;66(1):49-59.

44. Shevalye H, Yorek MS, Coppey LJ, et al. Effect of enriching the diet with menhaden oil or daily treatment with resolvin D1 on neuropathy in a mouse model of type 2 diabetes. J Neurophysiol. 2015;114(1):199-208.

45. Davidson EP, Coppey LJ, Shevalye H, Obrosov A, Kardon RH, Yorek MA. Impaired corneal sensation and nerve loss in a type 2 rat model of chronic diabetes is reversible with combination therapy of menhaden oil, $\alpha$-lipoic acid, and enalapril. Cornea. 2017;36(6):725-731.

46. Kramerov AA, Ljubimov AV. Stem cell therapies in the treatment of diabetic retinopathy and keratopathy. Exp Biol Med (Maywood). 2016; 241(6):559-568.

47. Ljubimov AV, Shaw LC, Li Calzi S, et al. The vascular stem cell. In: Dartt DA, Besharse JC, Dana R, editors. Encyclopedia of the Eye. San Diego, CA: Elsevier; 2010:289-299.

48. Shaw LC, Neu MB, Grant MB. Cell-based therapies for diabetic retinopathy. Curr Diab Rep. 2011;11:265-274.

49. Kojima H, Kim J, Chan L. Emerging roles of hematopoietic cells in the pathobiology of diabetic complications. Trends Endocrinol Metab. 2014;25(4):178-187. 
50. Megaw R, Dhillon B. Stem cell therapies in the management of diabetic retinopathy. Curr Diab Rep. 2014;14(7):498-506.

51. Saghizadeh M, Dib CM, Brunken WJ, Ljubimov AV. Normalization of wound healing and stem cell marker patterns in organ-cultured human diabetic corneas by gene therapy of limbal cells. Exp Eye Res. 2014; 129:66-73.

52. Saghizadeh M, Epifantseva I, Hemmati DM, Ghiam CA, Brunken WJ, Ljubimov AV. Enhanced wound healing, kinase and stem cell marker expression in diabetic organ-cultured human corneas upon MMP-10 and cathepsin F gene silencing. Invest Ophthalmol Vis Sci. 2013; 54(13):8172-8180

53. Kulkarni M, Leszczynska A, Wei G, et al. Genome-wide analysis suggests a differential microRNA signature associated with normal and diabetic human corneal limbus. Sci Rep. 2017;7(1):3448.

54. Lambiase A, Aloe L, Mantelli F, et al. Capsaicin-induced corneal sensory denervation and healing impairment are reversed by NGF treatment. Invest Ophthalmol Vis Sci. 2012;53(13):8280-8287.

55. Blanco-Mezquita T, Martinez-Garcia C, Proença R, et al. Nerve growth factor promotes corneal epithelial migration by enhancing expression of matrix metalloprotease-9. Invest Ophthalmol Vis Sci. 2013;54(6): 3880-3890.

56. Bian F, Qi H, Ma P, et al. An immunoprotective privilege of corneal epithelial stem cells against Th17 inflammatory stress by producing glial cell-derived neurotrophic factor. Stem Cells. 2010;28(12): 2172-2181.

57. Chen J, Chen P, Backman LJ, Zhou Q, Danielson P. Ciliary neurotrophic factor promotes the migration of corneal epithelial stem/progenitor cells by up-regulation of MMPs through the phosphorylation of Akt Sci Rep. 2016;6:25870.

58. Di G, Qi X, Zhao X, Zhang S, Danielson P, Zhou Q. Corneal epithelium-derived neurotrophic factors promote nerve regeneration. Invest Ophthalmol Vis Sci. 2017;58(11):4695-4702.

59. Park JH, Kang SS, Kim JY, Tchah H. Nerve growth factor attenuates apoptosis and inflammation in the diabetic cornea. Invest Ophthalmol Vis Sci. 2016;57(15):6767-6775.

60. Bikbova G, Oshitari T, Baba T, Yamamoto S. Neuronal changes in the diabetic cornea: perspectives for neuroprotection. Biomed Res Int. 2016; 2016:5140823.

61. Zhang M, Zhou Q, Luo Y, Nguyen T, Rosenblatt MI, Guaiquil VH. Semaphorin3A induces nerve regeneration in the adult cornea - a switch from its repulsive role in development. PLoS One. 2018;13(1): e0191962.
62. Sacchetti M, Lambiase A. Diagnosis and management of neurotrophic keratitis. Clin Ophthalmol. 2014;8:571-579.

63. Alvarez-Rivera F, Concheiro A, Alvarez-Lorenzo C. Epalrestat-loaded silicone hydrogels as contact lenses to address diabetic-eye complications. Eur J Pharm Biopharm. 2018;122:126-136.

64. Chen HF, Yeung L, Yang KJ, Sun CC. Persistent corneal epithelial defect after pars plana vitrectomy. Retina. 2016;36(1):148-155.

65. Fai S, Ahem A, Mustapha M, Mohd Noh UK, Bastion MC. Randomized controlled trial of topical insulin for healing corneal epithelial defects induced during vitreoretinal surgery in diabetics. Asia Pac J Ophthalmol (Phila). 2017;6(5):418-424.

66. Sosne G, Rimmer D, Kleinman HK, Ousler G. Thymosin beta 4: a potential novel therapy for neurotrophic keratopathy, dry eye, and ocular surface diseases. Vitam Horm. 2016;102:277-306.

67. Yang L, Di G, Qi X, et al. Substance P promotes diabetic corneal epithelial wound healing through molecular mechanisms mediated via the neurokinin-1 receptor. Diabetes. 2014;63(12):4262-4274.

68. Di G, Qi X, Zhao X, Zhang S, Zhou Q. Efficacy of sodium hyaluronate in murine diabetic ocular surface diseases. Cornea. 2017;36(9):1133-1138.

69. Morishige N, Uemura A, Morita Y, Nishida T. Promotion of corneal epithelial wound healing in diabetic rats by the fibronectin-derived peptide PHSRN. Cornea. 2017;36(12):1544-1548.

70. He J, Pham TL, Kakazu A, Bazan HEP. Recovery of corneal sensitivity and increase in nerve density and wound healing in diabetic mice after PEDF plus DHA treatment. Diabetes. 2017;66(9):2511-2520.

71. Guo C, Li M, Qi X, et al. Intranasal delivery of nanomicelle curcumin promotes corneal epithelial wound healing in streptozotocin-induced diabetic mice. Sci Rep. 2016;6:29753.

72. Atiba A, Wasfy T, Abdo W, Ghoneim A, Kamal T, Shukry M. Aloe vera gel facilitates re-epithelialization of corneal alkali burn in normal and diabetic rats. Clin Ophthalmol. 2015;9:2019-2026.

73. Wang W, Despanie J, Shi P, et al. Lacritin-mediated regeneration of the corneal epithelia by protein polymer nanoparticles. J Mater Chem B. 2014;2(46):8131-8141.

74. Zhou Q, Chen P, Di G, et al. Ciliary Neurotrophic Factor Promotes the Activation of Corneal Epithelial Stem/Progenitor Cells and Accelerates Corneal Epithelial Wound Healing. Stem Cells. 2015;33:1566-1576.

75. Waite JH, Beetham WP. The visual mechanism in diabetesmellitus (a comparative study of 2002 diabetics, and 457 non-diabetics for control). N Engl J Med. 1935;212:367-443.

76. Henkind P, Wise GN. Descemet's wrinkles in diabetes. Am J Ophthalmol. 1961;52:371-374.
Clinical Ophthalmology

\section{Publish your work in this journal}

Clinical Ophthalmology is an international, peer-reviewed journal covering all subspecialties within ophthalmology. Key topics include: Optometry; Visual science; Pharmacology and drug therapy in eye diseases; Basic Sciences; Primary and Secondary eye care; Patient Safety and Quality of Care Improvements. This journal is indexed on

\section{Dovepress}

PubMed Central and CAS, and is the official journal of The Society of Clinical Ophthalmology (SCO). The manuscript management system is completely online and includes a very quick and fair peer-review system, which is all easy to use. Visit http://www.dovepress.com/ testimonials.php to read real quotes from published authors. 